\title{
Correction to: Characterization and mapping spatial variability of Entisols derived from shale in Dakhla Oasis, Egypt
}

\author{
Salman Selmy ${ }^{1}$ - Salah Abd El-Aziz ${ }^{1} \cdot$ Mohsen Gameh $^{1} \cdot$ Al-Saadawi Abdelsalam ${ }^{1,2}$
}

Published online: 21 July 2020

(C) Saudi Society for Geosciences 2020

\section{Correction to: Arabian Journal of Geosciences} https://doi.org/10.1007/s12517-020-05540-2

The original version of this paper was published with error. Figure 3 were corrected into Figs. 3 and 4, but the old titles were used for these two figures and the updated captions which author sent in the last modification of the images were not used.

Given in this article are the correct captions.

The online version of the original article can be found at https://doi.org/ $10.1007 /$ s $12517-020-05540-2$

Salman Selmy

salman.selmy@agr.aun.edu.eg; salmansoils@yahoo.com

1 Department of Soils and Water, Faculty of Agriculture, Assiut University, Assiut 71526, Egypt

2 Department of Soils and Water, Faculty of Agriculture, Sirte University, Sirte, Libya 
Fig. 3 Subsurface cross-sections and spatial distribution maps of silt (a) and clay (b)
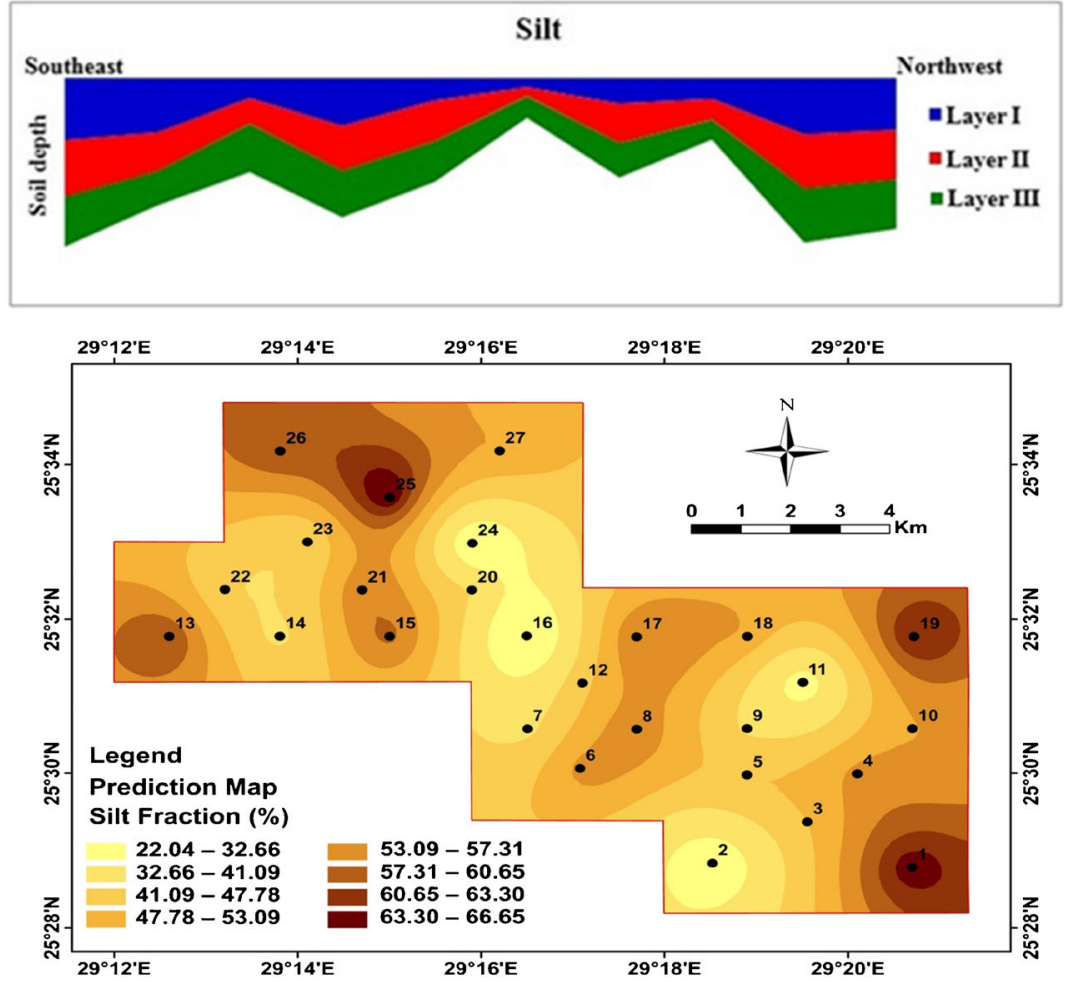

a
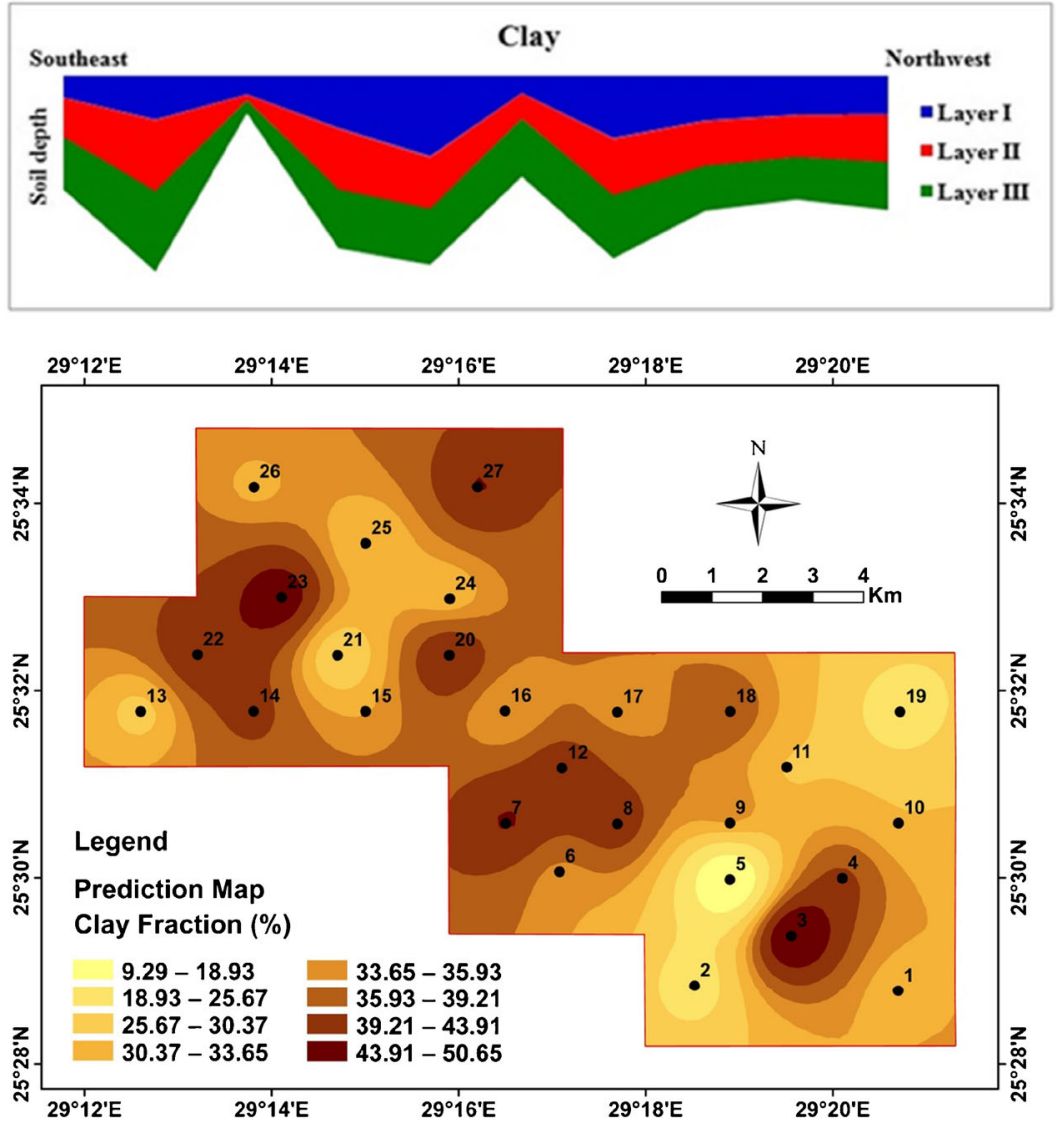

b 
Fig. 4 Subsurface cross-sections and spatial distribution maps of coarse sand, fine sand fractions (a) and soil texture (b)
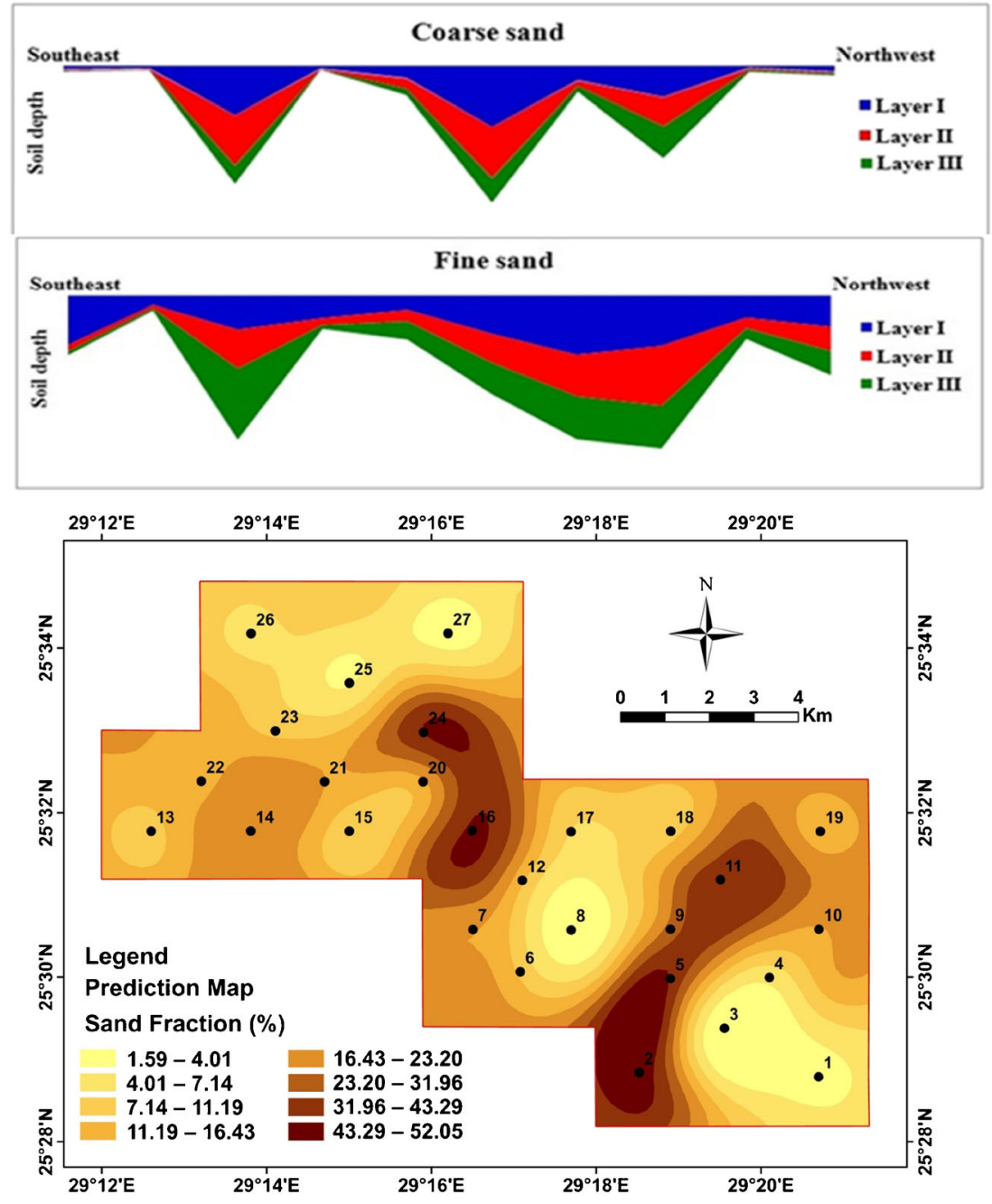

a

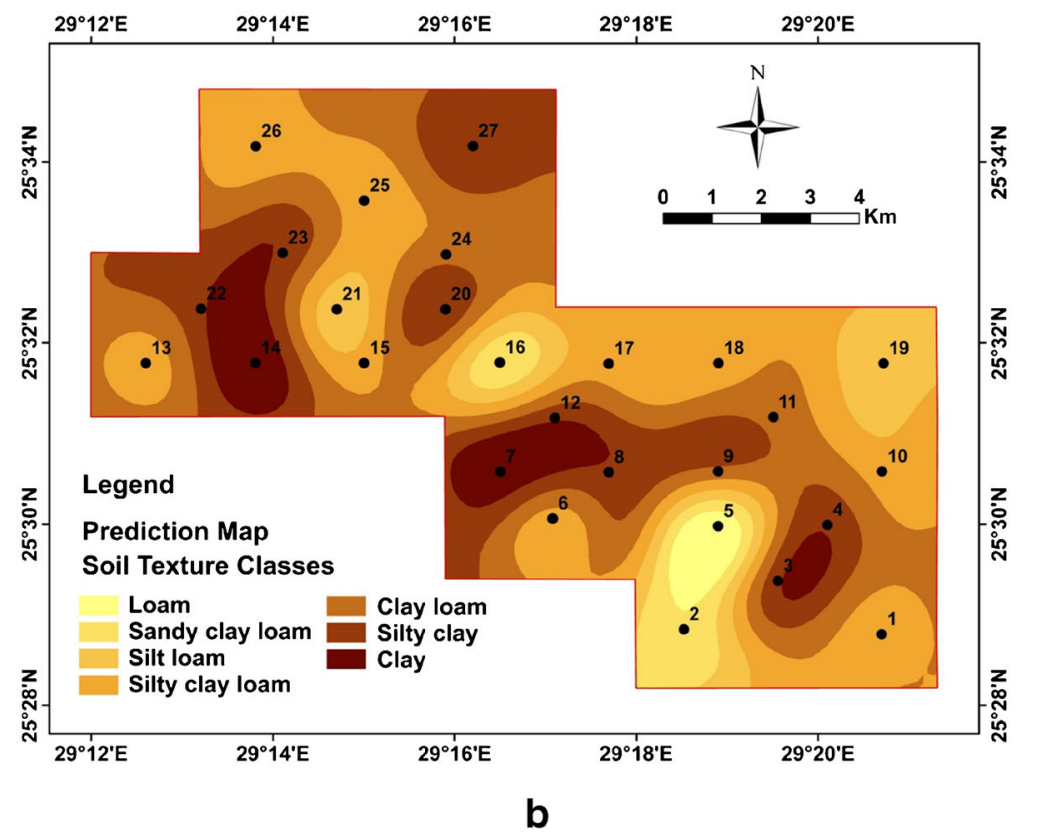

